\title{
Effects of aluminum (Al) incorporation on structural, optical and thermal properties of $\mathrm{ZnO}$ nanoparticles
}

\author{
NAShiruddin Ahammed ${ }^{1, *}$, Md SAmim Hassan $^{2}$, Mehedi Hassan $^{3}$ \\ ${ }^{1}$ Department of Physics, Muragachha Government College, Nadia-741154, West Bengal, India \\ ${ }^{2}$ Indian Institute of Technology Delhi, New Delhi-110016, India \\ ${ }^{3}$ Sensor and Actuator Division, CSIR-Central Glass and Ceramic Research Institute, Kolkata, W.B-700032, India
}

\begin{abstract}
In this research article, pure and $1 \%, 3 \%$ and $5 \%$ aluminium doped zinc oxide nanoparticles (NPs) were prepared via sol-gel method and then calcined at $500{ }^{\circ} \mathrm{C}$. X-ray diffraction (XRD), scanning electron microscope (SEM), Fourier transform infrared (FT-IR) spectroscopy, UV-Vis spectroscopy, thermogravimetric analysis (TGA) and differential scanning calorimetry (DSC) techniques were used to investigate the structural, optical and thermal properties of synthesized pure and $\mathrm{Al}$ doped $\mathrm{ZnO}$ nanoparticles. Energy dispersive X-ray spectroscopy (EDX) analysis revealed high purity of nanoparticles in the synthesized products without any impurity peaks. Mean dimension of the nanoparticles was $\sim 28 \mathrm{~nm}$ and they were hexagonal in shape, according to the images analyzed by transmission electron microscope (TEM). The optical absorption spectra of pure and Al doped $\mathrm{ZnO}$ samples studied using UV-Vis spectrometry have been presented and we have observed that the band gap increases with increasing $\mathrm{Al}$ concentration. In FT-IR spectra, the broad absorption peaks around $485 \mathrm{~cm}^{-1}$ and $670 \mathrm{~cm}^{-1}$ were assigned to $\mathrm{Zn}-\mathrm{O}$ vibration. Above $450{ }^{\circ} \mathrm{C}$, the TG curve became flat what means there was no weight loss. In the DSC curve it is seen that the transition at $150{ }^{\circ} \mathrm{C}$ was highly exothermic because of structural relaxation and on doping the exothermic peaks became shifted to the lower value of temperature. These types of materials are very useful in optoelectronics applications.
\end{abstract}

Keywords: Al doped ZnO; nanoparticles; sol-gel; XRD; band gap

\section{Introduction}

Scientists have been studying and working on nanoparticles for centuries, but the effectiveness of their work has been hampered by inability to characterize the structure of nanoparticles. In recent decades, the development of microscopes and different characterizing tools encouraged researchers worldwide to work in this field. Zinc oxide $(\mathrm{ZnO})$ is well known in scientific community. In the past 100 years, it has featured as a subject of thousands of research papers, dating back as early as 1935 . Valued for its ultraviolet absorbance, piezoelectricity and luminescence at high temperatures, $\mathrm{ZnO}$ has penetrated far into industry, and is one of the critical building blocks in today's modern society [1-4]. It can be found in paints, cosmetics, plastics and rubber manufacturing, gas sensors, electronics and pharmaceuticals, to name just a few. Pure $\mathrm{ZnO}$

*E-mail: nashiruddin73@gmail.com nanostructures show weak electrical conductivity due to their intrinsic semiconductor properties. But for many applications, e.g. gas sensing, photocatalysis, solar cells there is a need to increase the concentration of charge carriers; hence, to increase the conductivity.

More recently however, $\mathrm{ZnO}$ has again entered in the scientific spotlight, this time for its semiconducting properties [5]. With a wide band gap of $3.4 \mathrm{eV}$ and a large exciton binding energy of $\sim 60 \mathrm{meV}$ at room temperature, $\mathrm{ZnO}$ holds excellent promise for blue and ultraviolet optical devices. Zinc oxide is generally transparent to visible light but strongly absorbs ultraviolet light below $365 \mathrm{~nm}$. The absorption is typically stronger than of other white pigments. In the region of visible wavelengths, regular zinc oxide shows higher reactive index and thus has a superior opacity. Under ultraviolet light, zinc oxide is photoconductive. The combination of optical and semiconductor properties makes doped zinc oxide a contender 
for new generation of devices. Solar cells require a transparent conductive coating, indium tin oxide and zinc oxide (doped) are the best materials. Intrinsic optical properties of $\mathrm{ZnO}$ nanostructures are being intensively studied for implementing in photonic devices.

There is also a tremendous effect of doping of $\mathrm{ZnO}$ nanoparticles. A number of typical dopant elements such as F, B, Al, Ga, In and Sn have been used so far to produce various optical devices and conducting $\mathrm{ZnO}$ nanomaterials. It is worth to underline that among all the group III elements, $\mathrm{Al}$ is a cheap, abundant and non-toxic material allowing for realization of $\mathrm{ZnO}$-based photonic and optoelectronic devices, where, amongst other potential applications it stands also with gallium nitride $(\mathrm{GaN})$ as a prospective candidate for the next generation of light emitters for solid state lighting applications [6]. Gas sensors based on $\mathrm{Al}$ doped $\mathrm{ZnO}$ make use of chemical sensitivity of the surface to different adsorbed gases which cause a change in resistance of the sensor. Appropriate doping can provide electronic defects that increase the porosity and the grain size of polycrystalline zinc oxide material and have also noticeable effect on the gas sensitivity.

In our work, we synthesized pure and $\mathrm{Al}$ doped (1 wt.\%, 3 wt.\%, 5 wt.\%) $\mathrm{ZnO}$ by a simple solgel method. The XRD patterns show crystallinity and phase purity of pure and doped $\mathrm{ZnO}$ materials. With increasing $\mathrm{Al}$ concentration, the particle size is decreased due to lattice contraction. The band gap increases with increasing Al concentration because of combined effect of d-band movement and size confinement effects. Thermal analysis reveals the stability of the materials at high temperature [7].

\section{Experimental}

\subsection{Synthesis techniques}

All chemical reagents used in this experiment were of analytical grade. The initial materials included zinc nitrate $\left(\mathrm{Zn}\left(\mathrm{NO}_{3}\right)_{2}\right)$, aluminum nitrate $\left(\mathrm{Al}\left(\mathrm{NO}_{3}\right)_{2}\right)$, citric acid, liquid ammonia and ethanol. To the synthesis $\mathrm{Al}$ doped $\mathrm{ZnO}(0 \%, 1 \%$,
$3 \%$, and $5 \%$ ) NPs zinc nitrate and aluminium nitrate were used as starting materials. In a typical synthesis process, zinc nitrate and aluminum nitrate were dissolved in distilled water of $\mathrm{pH}$ below 2 maintained by adding citric acid under magnetic stirring at $80{ }^{\circ} \mathrm{C}$. Then, we added ammonia solution dropwise under constant stirring till the gel appeared. The gel was washed several times with ethanol and distilled water and dried at $120^{\circ} \mathrm{C}$ for overnight in an oven. The dried gel was ground in mortars to make fine powders. Then, these fine powders were annealed at $500{ }^{\circ} \mathrm{C}$ for 4 hours in the presence of air for phase ordering. Finally, Al doped $\mathrm{ZnO}$ NPs were formed.

\subsection{Characterizations}

The crystal nature, size and phase formation of $\mathrm{Al}$ doped $\mathrm{ZnO}$ NPs were examined by XRD (Rigaku Miniflex-II) using $\mathrm{CuK} \alpha$ radiation $(\lambda=1.5406 \AA)$, operated at a voltage of $30 \mathrm{kV}$ and a current of $15 \mathrm{~mA}$ in $2 \theta$ range from $20^{\circ}$ to $80^{\circ}$. The crystallite size has been determined using DebyeScherrer formula. The FT-IR spectra of the samples were recorded using PerkinElmer IR spectrophotometer with $\mathrm{KBr}$ pellets over the range $4000 \mathrm{~cm}^{-1}$ to $400 \mathrm{~cm}^{-1}$ to gain information of chemical bonding and functional groups. UV-Vis spectra of $\mathrm{Al}$ doped $\mathrm{ZnO}$ nanopowders for optical absorption measurement were performed in the range $250 \mathrm{~nm}$ to $800 \mathrm{~nm}$ using PerkinElmer spectrophotometer. The surface morphology and composition of the NPs were characterized by SEM (JEOL JSM6510LV) and EDX equipped with SEM, respectively. The particle size and morphology study were performed by using TEM (JEOL-JEM 2100). To study the thermal characteristics, TGA and DSC analyses have been performed.

\section{Results and discussion}

\subsection{XRD analysis}

The crystalline structure of the samples of pure $\mathrm{ZnO}$ and $\mathrm{Al}$ doped $\mathrm{ZnO}$ were investigated by X-ray diffraction using a Rigaku Miniflex II powder diffractometer. The peaks observed at $\left(\begin{array}{lll}1 & 0 & 0\end{array}\right)$, (l $\left.\begin{array}{lll}0 & 2\end{array}\right),\left(\begin{array}{lll}1 & 0 & 1\end{array}\right),\left(\begin{array}{lll}1 & 0 & 2\end{array}\right),\left(\begin{array}{lll}1 & 1 & 0\end{array}\right),\left(\begin{array}{lll}1 & 0 & 3\end{array}\right),\left(\begin{array}{lll}2 & 0 & 0\end{array}\right)$, 
( $\left.\begin{array}{lll}1 & 1 & 2\end{array}\right),\left(\begin{array}{lll}2 & 0 & 1\end{array}\right),\left(\begin{array}{lll}2 & 2 & 0\end{array}\right)$, and (4 000 ) indicate the presence of polycrystalline material. The crystallographic planes allow us to estimate the crystallite size calculated by Scherrer formula [8].

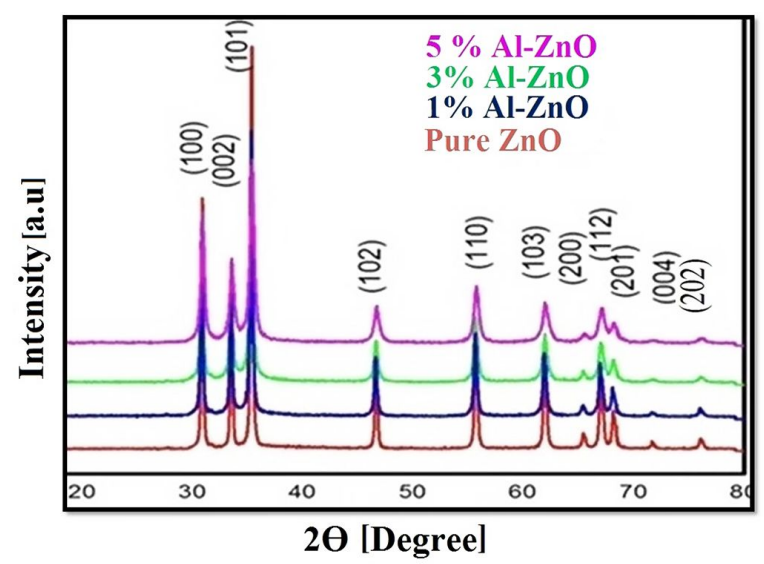

Fig. 1. XRD pattern of pure $\mathrm{ZnO}, 1 \%, 3 \%$, and $5 \% \mathrm{Al}$ doped $\mathrm{ZnO}$ nanoparticles calcined at $500{ }^{\circ} \mathrm{C}$.

Fig. 1 displays the XRD patterns of $\mathrm{ZnO}$ nanoparticles calcined at $500{ }^{\circ} \mathrm{C}$. All of the peaks match well with Bragg reflections of the standard hexagonal structure (International Centre for Diffraction Data: 04-0835). Fig. 1 shows $1 \%$, $3 \%$, and $5 \% \mathrm{Al}$ doped $\mathrm{ZnO} \mathrm{NPs}$, respectively, whose peaks are almost at same position as for pure $\mathrm{ZnO}$ nanoparticles and there is no appreciable peak shift up to $5 \% \mathrm{Al}$ concentration in $\mathrm{ZnO}$. The XRD results suggest that the nanopowders have a polycrystalline hexagonal wurtzite structure with well-developed crystallinity. In the XRD patterns, no other impurity peaks have been observed which shows the purity of the nanoparticles formation. The XRD analysis confirms that single phases of the $\mathrm{ZnO}$ and $\mathrm{Al}$ doped $\mathrm{ZnO}$ nanoparticles have been successfully synthesized using sol-gel method [9-14].

Crystallite size $t$ was calculated using Scherrer formula [15]:

$$
t=\frac{0.9 \cdot \lambda}{\beta \cos \theta}
$$

where $\lambda$ is the wavelength of $\mathrm{X}$-ray radiation, $\beta$ is full width at half maximum (FWHM) of the peaks at the diffraction angles $\theta$. The crystallite size for different $\mathrm{Al}$ concentrations in $\mathrm{ZnO}$ nanoparticles are shown in Table 1.

These results show that with increasing the amount of doping, the particle size is decreasing continuously under the same reaction conditions and the same reaction temperature. This is because the ionic radii of $\mathrm{Zn}$ and $\mathrm{Al}$ are respectively $0.054 \mathrm{~nm}$ and $0.074 \mathrm{~nm} \mathrm{[4]} \mathrm{which} \mathrm{provokes} \mathrm{a} \mathrm{dis-}$ order in the crystalline structure. This fact can also be associated with very slight change in the lattice parameter. We have successfully synthesized $\mathrm{Al}$ doped $\mathrm{ZnO}$ under the same synthesis conditions up to $5 \mathrm{~mol} \% \mathrm{Al}$ in $\mathrm{ZnO}$ without any extra peak which means that no secondary phase has appeared in the XRD pattern [16].

\subsection{SEM and EDX analyses}

SEM (JEOL JSM-6510LV) and EDX micrographs for the sample calcined at $500{ }^{\circ} \mathrm{C}$ are shown in Fig. 2. A small amount of $\mathrm{ZnO}$ nanoparticles has been dissolved in acetone for 1 hour under ultrasonication. Then, the sample was dried and put into a grinder to grind and made it into fine powder. Finally, we took the SEM image of that fine powder which is shown in Fig. 2a. Similar method was employed for $3 \mathrm{~mol} \% \mathrm{Al}$ in $\mathrm{ZnO}$ sample and its image is shown in Fig. 2c. It is clearly visible that the particles in pure $\mathrm{ZnO}$ are large compared to the doped $\mathrm{ZnO}$. All the particles are almost spherical in shape and the doped particles are more highly agglomerated than pure $\mathrm{ZnO}$.

For further confirmation of the presence of $\mathrm{Al}$ in $\mathrm{ZnO}$ we have characterized the $3 \mathrm{~mol} \%$ sample of $\mathrm{Al}$ doped $\mathrm{ZnO}$ with EDX and the presence of aluminum $\mathrm{Al}$, zinc $\mathrm{Zn}$ and oxygen $\mathrm{O}$ without any impurities was confirmed. From Fig. 2b and Fig. 2d it can be seen that no extra elements are present in the samples.

Fig. 3 clearly shows the amount of Al doping in $\mathrm{ZnO}$ NPs. Therefore, from these analyses we can say that we have successfully synthesized pure $\mathrm{ZnO}$ and $\mathrm{Al}$ doped $\mathrm{ZnO}$ nanoparticles without presence of any kind of impurities under the same synthesis conditions. 
Table 1. Crystallite size of different amount of doping of $\mathrm{ZnO}$ nanoparticles.

\begin{tabular}{cccc}
\hline $\begin{array}{c}\text { Al concentration in ZnO } \\
{[\mathrm{mol} \%]}\end{array}$ & $\begin{array}{c}\text { Crystallite } \\
\text { size }[\mathrm{nm}]\end{array}$ & $\begin{array}{c}\text { Lattice parameters a }=\mathrm{b} \\
{[\AA]}\end{array}$ & $\begin{array}{c}\text { Lattice parameters } \\
{[\AA]}\end{array}$ \\
\hline \hline 0 & 33 & 3.36 & 5.49 \\
1 & 27 & 3.32 & 5.43 \\
3 & 24 & 3.26 & 5.38 \\
5 & 19 & 3.24 & 5.31 \\
\hline
\end{tabular}

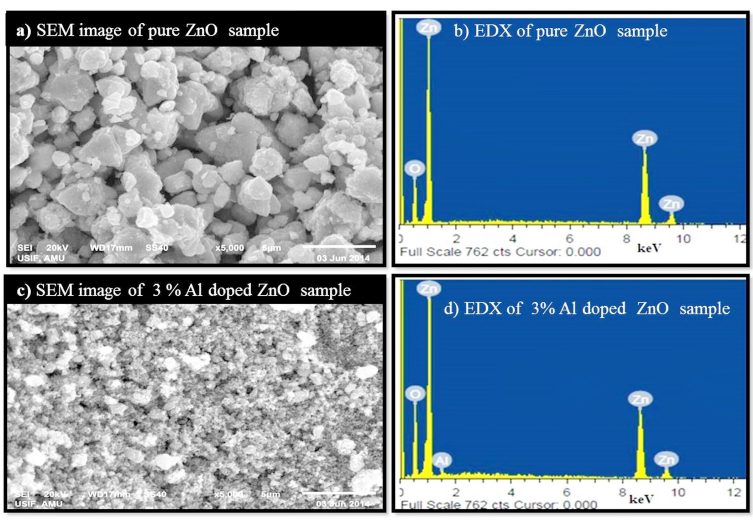

Fig. 2. SEM and EDX images of pure and $3 \% \mathrm{Al}$ doped $\mathrm{ZnO}$ nanoparticles.

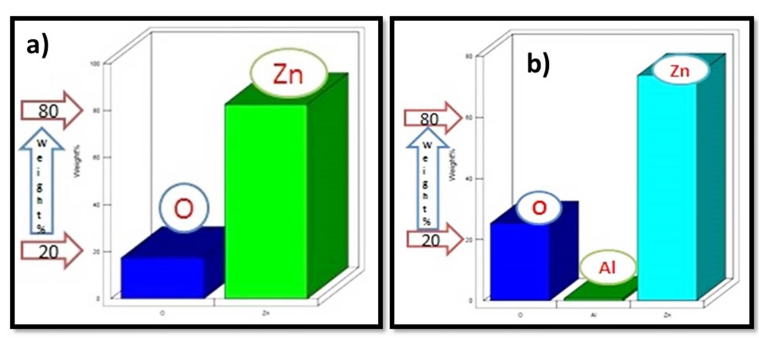

Fig. 3. (a) weight $\%$ versus composition of pure $\mathrm{ZnO}$ sample and (b) weight $\%$ vs. composition of $3 \%$ $\mathrm{Al}$ doped $\mathrm{ZnO}$ sample.

\subsection{TEM analysis}

In order to reveal the morphology and size of the synthesized products, a typical TEM (JEOL-JEM 2100) images have been recorded, as shown in Fig. 4. From the TEM images it can be clearly observed that the synthesized product consists of hexagonal shape grains with the size about $28 \mathrm{~nm}$ and some agglomerates. Finally, the particle sizes obtained from TEM are well matched with those measured from the XRD peak broadenings [17].

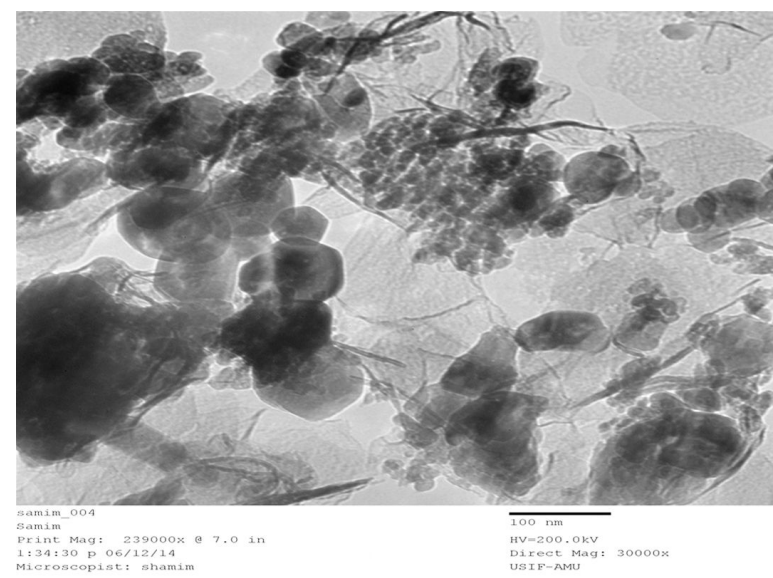

Fig. 4. TEM image of $1 \% \mathrm{Al}$ doped $\mathrm{ZnO}$ nanoparticles calcined at $500{ }^{\circ} \mathrm{C}$.

\subsection{UV-Vis spectra analysis and band gap calculation}

UV-Vis absorption spectra of pure $\mathrm{ZnO}$ and $\mathrm{Al}$ doped $\mathrm{ZnO}(1 \%, 3 \%$, and $5 \%$ ) nanoparticles have been studied with UV-Vis spectrometer (PerkinElmer Lamda35). A very small amount of $\mathrm{ZnO}$, up to $1 \% \mathrm{Al}$ doping, was dissolved in ethanol while the rest of the samples were dispersed in $\mathrm{N}$ methylpyrrolidine (NMP), as they do not dissolve in ethanol, and kept for ultrasonication for $15 \mathrm{~min}$. During the ultrasound treatment the agglomerated nanoparticles broke into individual nanoparticles, thus, homogeneous dispersion has been prepared.

The absorption spectra of this dispersion have been recorded using ethanol (for pure and $1 \%$ doped sample) and NMP (for $3 \%$ and $5 \% \mathrm{Al}$ doped sample). The plots of optical absorbance spectra of $0 \%, 1 \%, 3 \%$ and $5 \% \mathrm{Al}$ doped samples were characterized as a function of wavelength in Fig. 5. Fig. 5 shows strong absorption at wave 


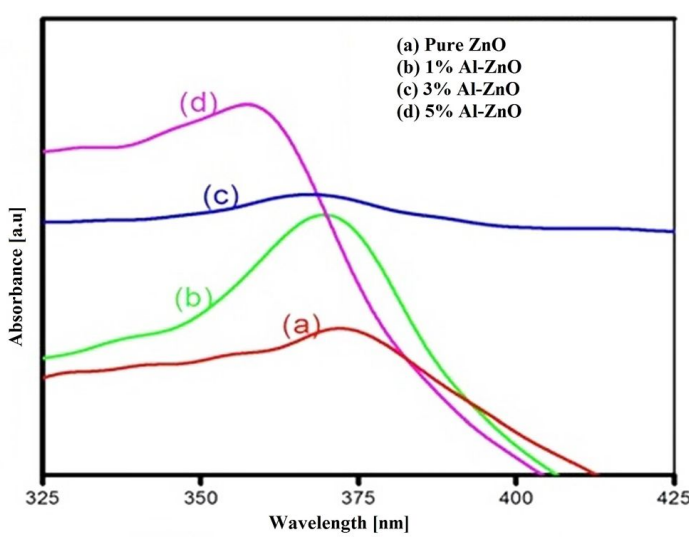

Fig. 5. UV-Vis absorbance of (a) pure $\mathrm{ZnO}$, (b) $1 \% \mathrm{Al}$ doped, (c) $3 \% \mathrm{Al}$ doped and (d) $5 \% \mathrm{Al}$ doped $\mathrm{ZnO}$ nanoparticles.

lengths $373 \mathrm{~nm}, 368 \mathrm{~nm}, 364 \mathrm{~nm}$ and $356 \mathrm{~nm}$. The absorption edges are found to shift towards lower wavelengths, i.e. higher energies with an increase in $\mathrm{Al}$ concentration.
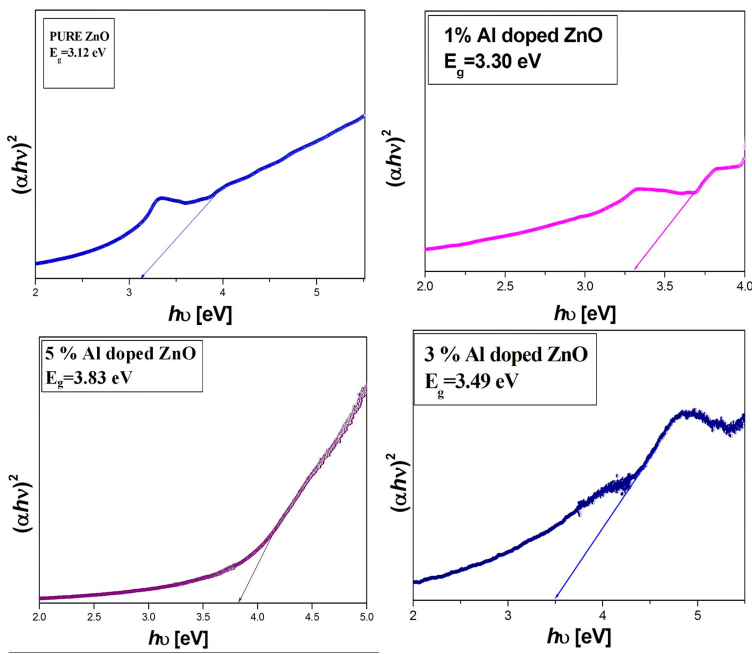

Fig. 6. Tauc plots to estimate band gap of pure $\mathrm{ZnO}$ and Al doped $\mathrm{ZnO}$ NPs.

The optical band gap was also evaluated from the experimental results using the Tauc relationship [10]:

$$
\begin{gathered}
\alpha h v=\left(h v-E_{g}\right)^{n} \\
(\alpha h v)^{2}=B\left(h v-E_{g}\right) \text { for } n=1 / 2
\end{gathered}
$$

where $\alpha$ is the absorption coefficient, $\mathrm{E}_{\mathrm{g}}$ is energy band gap of semiconductor and $n=1 / 2$ or 2 , for allowed transitions for direct or indirect band gap semiconductor, respectively and B is the characteristic parameter for respective transitions, regardless of photon energy hu.

Table 2. Band gap measurement of pure $\mathrm{ZnO}$ and $\mathrm{Al}$ doped $\mathrm{ZnO}$.

\begin{tabular}{cc}
\hline $\begin{array}{c}\text { Al concentration in } \mathrm{ZnO} \\
{[\mathrm{mol} \%]}\end{array}$ & $\begin{array}{c}\text { Band gap } \\
{[\mathrm{eV}]}\end{array}$ \\
\hline \hline $0 \%$ & 3.12 \\
$1 \%$ & 3.30 \\
$3 \%$ & 3.49 \\
$5 \%$ & 3.83 \\
\hline
\end{tabular}

The band gap calculation results are given in Table 2. Band gap graphs were plotted in the linear region near the onset of $(\alpha h v)^{2}$ versus $h v$ which is shown in Fig. 6.

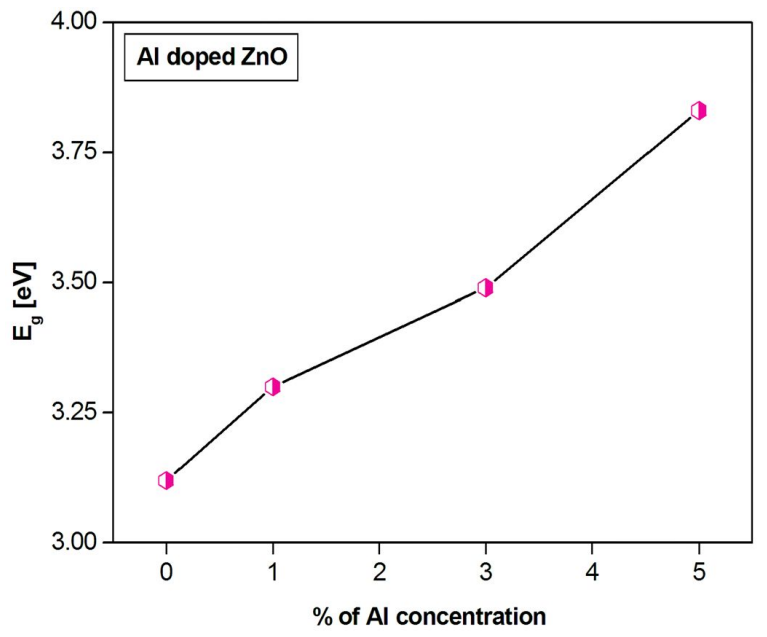

Fig. 7. Energy band gap variation with aluminum $\mathrm{Al}$ concentration in $\mathrm{ZnO}$ NPs.

Small changes in the optical band gap with the change in doping concentration have been shown in the Fig. 7. The results show that the pure $\mathrm{ZnO}$ has a band gap of $\sim 3.12 \mathrm{eV}$, which increases with an increase in $\mathrm{Al}$ concentration.

This change in the band gap has been explained on the basis of the decrease in the size with increasing the amount of doping up to $5 \% \mathrm{Al}$. Since 
the ionic radii of $\mathrm{Zn}$ and $\mathrm{Al}$ are, respectively, $0.054 \mathrm{~nm}$ and $0.074 \mathrm{~nm}$, so the particle size of $\mathrm{Al}$ doped $\mathrm{ZnO}$ is decreasing continuously up to a certain degree of doping. According to quantum confinement theory, the band gap of a semiconductor depends on crystal size, and its value will increase as the crystal size decreases. This is also explained by the band theory $[11,18]$ and Burstein-Moss effect [19]. Coulomb interaction predicts that the top of the valence band consists of the oxygen $2 p$ band and the bottom of the conduction band is mainly derived from $\mathrm{Zn} 3 \mathrm{~d}$ states and also $\mathrm{Al}$ derived from $3 p$ states. The energy band structure suggests that the absorption peak arises from $2 p$ states of oxygen to $3 \mathrm{~d}$ states of $\mathrm{Zn}$ [8]. The increase in $\mathrm{E}_{\mathrm{g}}$ with increasing $\mathrm{Al}$ content in $\mathrm{ZnO}$ is attributed to these orbital interactions giving rise to band gap [18].

\subsection{FT-IR analysis}

FT-IR (PerkinElmer spectrum) is an experimental technique in which identification of a compound is done on the basis of the bond strength considering their symmetric and anti-symmetric stretching and bending modes [10]. Here, we characterized the $0 \%, 1 \%, 3 \%$, and $5 \% \mathrm{Al}$ doped $\mathrm{ZnO}$ sample and recorded the data as shown in Fig. 8.

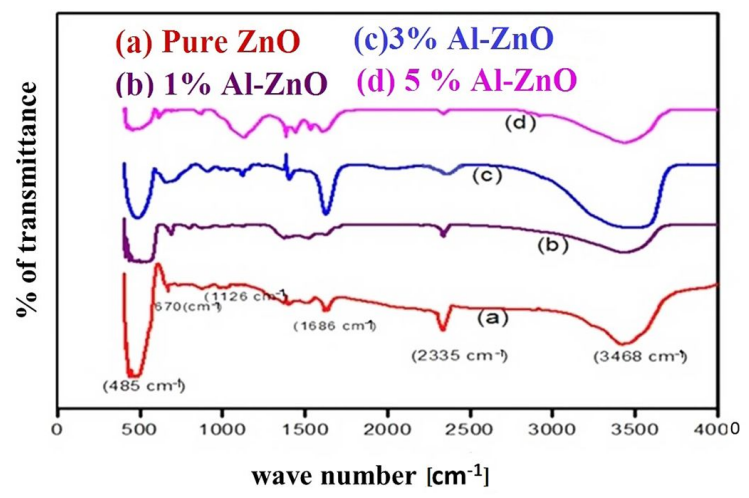

Fig. 8. FT-IR patterns of pure and $\mathrm{Al}$ doped $\mathrm{ZnO}$ nanoparticles.

Metal oxides generally give absorption bands in fingerprint region, i.e. below $1000 \mathrm{~cm}^{-1}$ arising from interatomic vibrations. The peaks observed at approximately $3466 \mathrm{~cm}^{-1}$ and $1126 \mathrm{~cm}^{-1}$ are due to
$\mathrm{O}-\mathrm{H}$ stretching and deformation frequency assigned to water adsorption on the metal surface. The peaks arising approximately at $485 \mathrm{~cm}^{-1}$ and $670 \mathrm{~cm}^{-1}$ correspond to symmetric and asymmetric $\mathrm{Zn}-\mathrm{O}$ vibration, respectively. The peak at $1686 \mathrm{~cm}^{-1}$ is due to the $\mathrm{C}=\mathrm{O}$ bond which may be the reason for the absorption of $\mathrm{CO}_{2}$ by the $\mathrm{KBr}$ as $\mathrm{KBr}$ is a good $\mathrm{CO}_{2}$ adsorbent. The peak at $2335 \mathrm{~cm}^{-1}$ is due to the formation of $\mathrm{M}-\mathrm{C}=\mathrm{O}^{+}$ by the metal $\mathrm{M}$ oxide bond after absorption of $\mathrm{CO}_{2}$ and is mainly assigned to the carbon oxygen triple bond [20, 21]. Here, there is a change in the position as well as the absorbance of the peak with doping. This clearly indicates that there is a change in the bond strength with the doping element.

\subsection{TGA and DSC analysis}

Thermogravimetric analysis (TGA) was carried out using a PerkinElmer (Pyris1) thermal analyzer. The thermogravimetric analysis is used to study thermal characteristics of a product. Here, the samples were kept at $50{ }^{\circ} \mathrm{C}$ for $1 \mathrm{~min}$, and then the temperature was raised from $50{ }^{\circ} \mathrm{C}$ to $800{ }^{\circ} \mathrm{C}$ at a rate of $10^{\circ} \mathrm{C} / \mathrm{min}$.
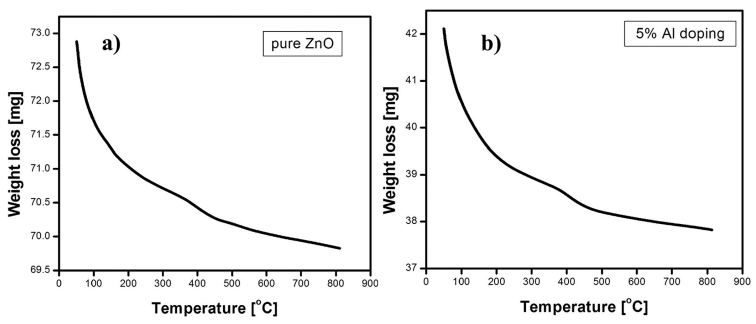

Fig. 9. (a) TGA curve of pure $\mathrm{ZnO}$ nanoparticles and (b) TGA curve of of $5 \% \mathrm{Al}$ doping $\mathrm{ZnO}$ nanoparticles

It can be seen from Fig. 9 that the weight loss occurs in two temperature regions, $50{ }^{\circ} \mathrm{C}$ to $200{ }^{\circ} \mathrm{C}$ and $200{ }^{\circ} \mathrm{C}$ to $450{ }^{\circ} \mathrm{C}$ for pure $\mathrm{ZnO}$ and for $5 \%$ $\mathrm{Al}$ doped sample it occurrs at $50{ }^{\circ} \mathrm{C}$ to $200{ }^{\circ} \mathrm{C}$ and $200{ }^{\circ} \mathrm{C}$ to $460{ }^{\circ} \mathrm{C}$.

We can see from the TGA curve that $5 \%$ loss occurs for pure $\mathrm{ZnO}$ and $7.5 \%$ loss takes place in case of $5 \% \mathrm{Al}$ doped $\mathrm{ZnO}$. The weight loss below $200{ }^{\circ} \mathrm{C}$ is due to the removal of loosely bound water of the sample. The decomposition step between 
$200{ }^{\circ} \mathrm{C}$ to $460{ }^{\circ} \mathrm{C}$ is due to oxidative decomposition of the material, i.e. decomposition of the $\mathrm{Zn}(\mathrm{OH})_{2}$, which is formed by absorption of water, and then is converted to $\mathrm{ZnO}$. Here, the decomposition of the $\mathrm{Al}$ doped $\mathrm{ZnO}$ is larger as compared to their pure counterpart which indicates that the doping material absorbed more water. The higher thermal stability may be due to the effect of high crystallization of the material. The small loss indicates less defects in the materials $[22,23]$.

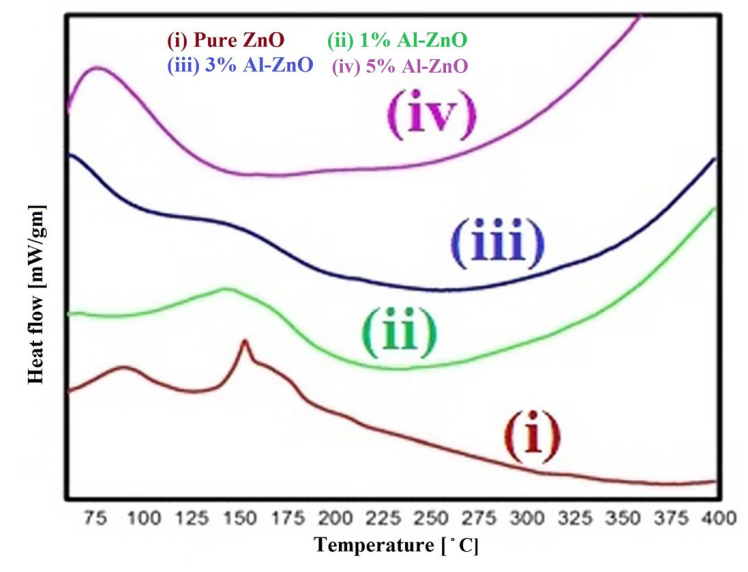

Fig. 10. DSC curves of pure and $\mathrm{Al}$ doped $\mathrm{ZnO}$ nanoparticles.

Differential scanning calorimetry or DSC is a thermoanalytical technique in which the difference in the amount of heat required to increase the temperature of a material is measured as a function of temperature and compared to the reference. Here, we can measure the transition state of the material. Fig. 10 shows clear transition around $150{ }^{\circ} \mathrm{C}$. Here, the upper peak indicates that the material absorbs more heat as compared to the reference sample which corresponds to the exothermic transition of the material. There is a certain shift of the peak to the left in the doped materials as compared to the pure material, which shows that the exothermic transition occurs at a lower temperature in case of doping [12].

\section{Conclusions}

We have successfully synthesized pure and $\mathrm{Al}$ doped $\mathrm{ZnO}$ nanoparticles from nitrate precursors by sol-gel method up to $5 \% \mathrm{Al}$ doping and calcined them at $500{ }^{\circ} \mathrm{C}$. XRD analysis confirmed the single phase polycrystalline wurtzite type structure matching with the standard value. The size of the crystallites decreased gradually with increasing $\mathrm{Al}$ concentration up to $5 \mathrm{~mol} \%$. EDAX results revealed the purity of the materials. TEM images showed that the synthesized Al doped $\mathrm{ZnO}$ product was composed of nanoparticles with hexagonal shape and the size about $28 \mathrm{~nm}$. In FT-IR spectra, the absorption peak in the region of $485 \mathrm{~cm}^{-1}$ to $670 \mathrm{~cm}^{-1}$ was assigned to $\mathrm{Zn}-\mathrm{O}$ vibration. In DSC curve, the transition at $150{ }^{\circ} \mathrm{C}$ was highly exothermic because of structural relaxation. TGA analysis showed a weight loss around $200{ }^{\circ} \mathrm{C}$ due to the water loosing and another loss around $450{ }^{\circ} \mathrm{C}$ due to the oxidative decomposition. The optical absorption spectra of pure and aluminum doped zinc oxide samples were measured with a UV-Vis spectrometer and energy band gap increased from $3.12 \mathrm{eV}$ to $3.83 \mathrm{eV}$ with increasing $\mathrm{Al}$ concentration up to $5 \mathrm{~mol} \%$ in $\mathrm{ZnO}$ which may be used in various photonic and optoelectronic devices.

\section{Acknowledgements}

The authors are thankful to the Centre of Excellence in Materials Science (Nanomaterials) in the Department of Applied Physics, Faculty of Engineering and Technology, AMU, Aligarh, India, for providing us the experimental facilities and financial support for this work. One of the authors, Md Samim Hassan, is also thankful to the University Sophisticated Instruments Facility (USIF), Aligarh Muslim University, Aligarh, India, for allowing to use TEM and SEM equipped with EDX.

\section{References}

[1] Orlinskit S.B., Schmidt J., Baranov P.G., LorMann V., Riedel I., Rauh D., Dyakonov V., Phys. Rev. B, 77 (2008), 115334.

[2] Mehedi H.M., Wasi K., Ameer A., Naqvi A.H., J. Lumin., 145 (2014), 160.

[3] Huiria M., Mira el L., Leonardic S.G., Pistonec A., Maviliad L., Neric G., , Sensor. Actuat. B-Chem., 196 (2014), 413.

[4] Hewakuruppu Y.L., Dombrovsky L.A., Chen C., Timchenko V., Jiang X., Baek S., TAYlor R.A., Appl. Optics, 52 (24) (2013), 6041.

[5] Look D.C., Mater. Sci. Eng. B-Adv., 80 (2001), 383.

[6] Titkov I.E., Delimova L.A., Zubrilov A.S., Seredova N.V., LinitChuK I.A., Grekhov I.V., J. Mod. Optic., 56 (2009), 653.

[7] Imran K., Shakeel K., Wasi K., Mat. Sci. Semicon. Proc., 14 (2014) 516. 
[8] Wasi K., Khan Z.A., SaAd A.A., Shervani S., Saleem A., Naqvi A.H., Int. J. Mod. Phys. A, 22 (2013), 630.

[9] Craciun V., Elders J., Gardeniers J.G.E., Boyd I.W., Appl. Phys. Lett., 65 (1994), 2963.

[10] Ganachari S.V., Bhat R., Deshpande R., Venkataraman A., Recent Res. Sci. Tech., 4 (2012), 50.

[11] Imran K., Shakeel K., Razia N., Hilal A., WASI K., Opt. Mater., 35 (2013), 1189.

[12] DeAn J.A., The Analytical Chemistry Handbook, McGraw-Hill Inc., New York, 1995..

[13] Khalid O., Ooi M.D.J., Hassin M.M., Mod. Appl. Sci., 3 (2009), 110.

[14] Sumaira M., Sahanawaze A.M., Imuddin A., Physica B, 430 (2013), 106.

[15] Mallick P., Rath C., Biswal R., Mishra N.C., Indian J. Phys., 83 (2009), 517.

[16] Chen Y., Bagnall D.M., KoH H.K., Park K.T., Hiraga K., Zhu Z.Q., Yao T., J. Appl. Phys., 84 (1998), 3912.
[17] Alagiri M., Ponnusamy S., MuthamizhchelVAN C, J. Mater. Sci.-Mater. El., 23 (2012), 728.

[18] Navale S.C., Ravi V., SRinivas D., Mulla I.S., Gosavi S.W., Kulkarni S.K., Sensor. Actuat. BChem., 130 (2008), 668.

[19] Kim C.E., Moon P., Kim S., Myoung J.-M., Jang H.W., BANG J., YUN I., Thin Solid Films, 581 (2010), 6304.

[20] Guan H., Shao C., Wen S., Chen B., Gong J., YANG X., Inorg. Chem. Commun., 6 (2003), 1302.

[21] Patil P.S., Kadam L.D., Appl. Surf. Sci., 199 (2002), 211.

[22] Conts A.W., Redfern J.P., Analyst, 88 (1963), 906.

[23] Gilbert J.B., Kipling J.J., McEnaney B., Sherwood J.N., Polymer, 3 (1962), 1.

Received 2017-05-19

Accepted 2018-02-06 